\title{
Role of stigmasterol and folic acid in improving the growth and yield of flax under drough
}

\author{
Nemat M. Hassan*, Zeinab M. El-bastawisy, Enas G. Badran, Ebtesam M. Hamady \\ ${ }^{1}$ Botany and Microbiology Department, Faculty of Science, Damietta University, Damietta, Egypt.
}

Received: 3 March 2016/ Accepted: 15 May 2016

*Corresponding author: nematmhassan@yahoo.com

\begin{abstract}
Seeds of flax (Linum usitatissimum L., Giza 9) were soaked in $5 \mathrm{ml}$ of either tap water, stigmasterol (100 ppm) or folic acid(200 ppm) for 12 hand then sown in clay/sand soil (2/1, w/w) in plastic pots. On the 24th day after sowing (24 DAS), water regime was applied as the first group was divided into 2 parts, one watered weekly (control) and the other watered every 2 weeks (drought) while both soaked groups were watered every 2 weeks (drought+stigmasterol) and (drought+folic acid), respectively and samples were taken until seed harvest. Drought resulted in a significant decrease in shoot height and root length, fresh and dry weights of shoot and root, leaf number, number of capsules and seeds and photosynthetic pigments contents. Meanwhile, total insoluble sugars and protein were significantly decreased; however, increases were detected in total soluble sugars, proline, lipid peroxidation and $\mathrm{H} 2 \mathrm{O} 2$. Seed priming with either stigmasterol or folic acid caused an increases in fresh and dry weights, leaf number, number of capsules, number of seeds and protein content comparing with stressed plants but without reaching control values concomitant with an enhancement in proline accumulation and decreases in $\mathrm{H} 2 \mathrm{O} 2$ and lipid peroxidation. These findings conclude that presoaking of flax seeds with stigmasterol or folic acid improved to some extent- plant growth under drought due to the improvement of photosynthetic apparatus and anabolic processes synchronous with alleviation of oxidative stress and elevation of proline with its role in osmoregulation.
\end{abstract}

Keywords: Drought stress, Stigmasterol, Folic Acid, Growth and yield, Flax.

\section{Introduction}

Flax (Linum usitatissimum L.) is an important source of natural fibers and industrial oil, and has the potential of meeting edible oil and protein deficiency (Ibrahim, 2009). Environmental stresses limit agricultural productivity worldwide (Nakayama et al., 2007). Water deficits at the flowering and the post-flowering stages have been found to have a greater adverse impact than that at the vegetative stage (Rafiei Shirvan and Asgharipu, 2009). Water stress also affects cellular membranes and organelles (Candan, et al 2003). Malondialdehyde (MDA, a product of lipid peroxidation) is regarded as a biomarker for evaluation of the damages in plasma lemma and organelle membranes caused by oxidative stress. MDA content in plants increases under environmental stresses, the better oxidative stress tolerance is accompanied with lower MDA levels (Verbruggen and Hermans 2008). 
Tolerance to abiotic stresses is very complex, due to the intricate of interactions between stress factors and various molecular, biochemical and physiological phenomena affecting plant growth and development (Razmjoo et al., 2008). Improving drought resistance is therefore, a major objective in plant breeding programs for agriculture in these regions (Ahmadizadeh, et al., 2011). Phytosterols and vitamins are known to improve plant growth and development. Beneficial effects of vitamins on yield quantity and quality have been reported for various crops (Jaleel et al., 2009).

Phytosterols are triterpenes with similar chemical structure and biological functions as cholesterol (Piironen et al., 2000). They are important structural components of plant membranes, and free phytosterols serve to stabilize phospholipid bilayers in plant cell membranes just as cholesterol does in animal cell membranes. The most abundant plant sterols are sitosterol, campesterol and stigmasterol. In plant cells, they contribute to the regulation of the fluidity and permeability of cell membranes, and act as substrates for the synthesis of numerous secondary plant metabolites for biogenic precursors of compounds involved in growth (Hartmann, 2009). Sterols play an important role in plant development including cell expansion, vascular differentiation, etiolation and reproductive development (Abd El-Wahed et al., 2001, Rao et al., 2002). A remarkable feature of brassinosteroids is their potential to increase plant resistance to a wide spectrum of biotic and abiotic stress conditions (Hasnaa et al., 2009 and Gruszka 2013).

Folic acid is one of the B-complex vitamins. It is a form of the water-soluble vitamin B9. Folic acid is a key factor in amino acids metabolism and nucleic acids biosynthesis (Andrew et al., 2000). These compounds have beneficial effects on catching the free radicals or the active oxygen that producing during photosynthesis and respiration processes (Fard et al., 2008). Vitamins have also, an auxinic action. The beneficial effects of different vitamins on growth and production of field crops were established (Al- Qubaie, 2012). So, the objective of this study was to investigate the effect of presoaking of flax seeds in either stigmasterol or folic acid on improving the growth and yield quantity of the plant grown under drought stress condition by withholding water.

\section{Materials and Methods}

\section{Plant Materials and growth conditions}

Seeds of flax (Linum usitatissimum L, Giza 9), kindly obtained from Agricultural Research Center (ARC), Giza, Egypt , surface sterilized and divided into three groups; the first group was soaked in $5 \mathrm{ml}$ tap water. Seeds of the other two groups were soaked either in $5 \mathrm{ml} 100 \mathrm{ppm}$ solution of stigmasterol or in $5 \mathrm{ml} 200 \mathrm{ppm}$ folic acid. After $12 \mathrm{~h}$ in the soaking solutions, seeds were spread on a filter paper overnight for airdrying and then sown in plastic pots $(40 \mathrm{~cm}$ in diameter) filled with clay/sand soil $(2 / 1, w / w)$. All pots were irrigated with tap water every 4 days until emergence and then thinned on the $18^{\text {th }}$ DAS to 20 seedlings per pot and full strength nutrient Ashton solution was applied only once $(600 \mathrm{ml} / \mathrm{pot})$. On the $24^{\text {th }} \mathrm{DAS}$, water regime was applied as the first group was divided into 2 parts, one watered weekly (control) and the other watered every 2 weeks (drought) also both soaked groups were watered every 2 weeks (drought+stigmasterol) and (drought+folic acid), respectively and samples were taken until harvest at seed maturity (about 5months).

The experiment was replicated three times and allowed growing in the green house under sunlight and natural growth conditions for flax cultivation period from November to April. Samples were harvested just before starting water regime (24 DAS) and every 10 days during seedling stage (55DAS) but capsules and seeds were collected at the end of the experiment (150 DAS). Shoots and roots were separated and used for growth parameters measurements as shoot height, root length as well as fresh and dry weights of shoots and roots. Shoots were collected, frozen immediately in liquid nitrogen and stored at $80^{\circ} \mathrm{C}$ for subsequent biochemical analyses. 


\section{Determination of photosynthetic pigments content}

Chlorophylls a, b and carotenoids content composition was measured by a double-beam spectrophotometer according to Lichtenthaler and Wellburn (1983).

\section{Determination of total soluble and insoluble sugars}

About $0.05 \mathrm{~g}$ of the oven dry sample were grounded in mortar, and then extracted with $5 \mathrm{ml}$ of $80 \%$ ethanol overnight (Schortemyer et al., 1997).

\section{Determination of total protein content}

The protein content was determined spectrophotometrically using a double beam recording spectrophotometer according to the method adopted by Bradford (1976).

\section{Determination of proline content:}

Proline was estimated as described by Bates et al., (1973).

\section{Determination of hydrogen peroxide}

$\mathrm{H}_{2} \mathrm{O}_{2}$ was measured according to Alexieva et al., (2001).

\section{Determination of lipid peroxidation}

Lipid peroxidation in leaves was assayed by measuring the malondialdehyde (MDA) content according to Heath and Paker (1968).

\section{Statistical analysis}

Data were analyzed using SPSS version 22. The effects of main factors (drought, treatment and plant age) and their interaction were assessed by using three-way ANOVA. Mean separation was performed using the Duncan's multiple range test at $\mathrm{p}<0.05$. (Carver and Nash, 2011).

\section{Results and Discussion}

Shoot height and root length of the flax either control or treated was gradually increased with the progress in time. Drought stress resulted in a significant decrease in shoot height nearly along the experimental period comparing the corresponding control values especially at last two harvests. Presoaking with folic acid caused a significant increase in shoot height on the $45^{\text {th }}$ DAS comparing with drought stressed plants. Also, root length was significantly decreased due to drought stress comparing with control values in all harvests in spite of the significant increase observed at the end of the experiment. Seed priming with either stigmasterol or folic acid significantly increased root length during the $1^{\text {st }}$ and the $2^{\text {nd }}$ harvest, respectively comparing the corresponding values of plants under drought stress. The decrease in shoot length by drought was reported (Demirevska et al., 2009). Sterols play an important role in plant development including cell expansion and vascular differentiation (Rao et al., 2002). In accordance with our results, Emam et al. (2011) found that the applied vitamins had a general enhancement effect on growth of stressed flax seedlings.

Fig.1 also shows a progressive increase in fresh weight of shoot and roots either in treated or non-treated plants along the duration of the experiments. Drought caused severe loss in shoot fresh weight; this decrease was most pronounced at the last two harvests. Also root fresh weight was significantly decreased starting from day 45 DAS till the end of the experiment comparing the corresponding control values. These results are in accordance with Sayar et al. (2010). Presoaking with either stigmasterol or folic acid caused a significant increase in shoot fresh weight. Folic acid caused also an increase in root fresh weight in comparison with stressed plant mainly in the last two harvests; nonetheless, stigmasterol had no significant effect. Similar results were obtained by Abd El-Wahed et al. (2001), who found that both stigmasterol and spermidine caused stimulation of vegetative growth characteristics (plant height, leaf area, plant fresh and dry weight).

Similarly, there was a progressive accumulation in dry weight content of shoot and root in control and stressed flax with increasing time (Fig.1). Drought diminished dry weight of shoots and roots from the $45^{\text {th }}$ DAS onward, the decrease was mostly severe at last harvest. The decrease in dry weight may be due to the considerable decrease in plant growth, photosynthesis and canopy structure as indicated by leaf senescence during drought stress (Sankar et al., 2007). There was not any significant change in shoot dry weight due to pretreatment 
with stigmasterol or folic acid, however, a significant increase was detected in dry weight due to folic acid as compared to corresponding values of stressed plants suggesting that folic acid is more effective upon growth of root than shoot. In this context, Hashem et al. (2011) found that application of stigmasterol improved the growth of Linum usitatissimum plants by causing significant increases in the values of shoot length, area of leaves, freshand dry weights of shoots as compared with the corresponding controls. This improvement is probably due to increasing the efficiency of water uptake and utilization, enhancing cell division and/or cell enlargement, resulting in longer shoots and roots and increasing leaf area which, consequently, increased the fresh and dry matter of root and shoots, presumably, as a result of larger surface area available for anabolic activities. Similar results were obtained by Abd El-Wahed et al. (2001), who found that both stigmasterol and spermidine caused stimulation of vegetative growth characteristics (plant height, leaf area, plant fresh and dry weight) and net assimilation rate and vascular bundles differentiation of wheat.
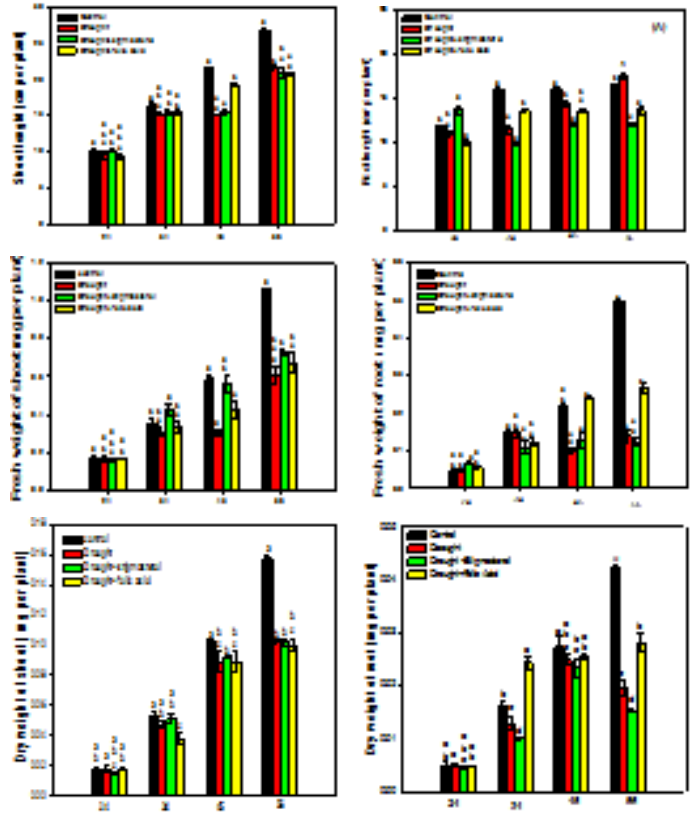

Days After Sawing (DAS)

Fig. 1 Changes in shoots and roots length, fresh and dry weights of shoots and roots of flax cultivar (Giza9) as a result of drought stress alone or in combination with stigma sterol or folic acid. Data are means of three replicates \pm SE. Bars labeled with different letters are significantly different at $P<0.05$

In Fig. 2, leaf number either in control or treated flax was gradually increased with increasing time. Drought decreased leaf number only at the last two harvests comparing control values. Development of leaves and their optimal area are important to photosynthesis and dry matter yield. Water deficit mostly reduced leaf growth and in turn the leaf areas in many species of plant (Farooq et al., 2009). Seed Priming with Either stigmasterol or folic acid significantly increased leaf number only at the last harvest compares drought stressed plants. Naheif (2013) declared that the beneficial effect of different vitamins on growth and production of field crops. Moreover, the beneficial effects of phytosterols might come from their role as biogenic precursors of compounds involved in plant growth (Hartmann, 2009).

At the end experiment (150 DAS) number of capsules was recorded and presented in Fig. 2. Drought stress significantly decreased number of capsules in flax cultivar. Water stress during vegetative phase reduces grain yield through restricted plant size, leaf area and root growth which subsequently reduces the dry matter accumulation, number of pods per plant and low harvest index. Nouri-Ganbalani et al., (2009) indicated that water deficits at the flowering and the post-flowering stages have a greater adverse impact than that at the vegetative stage. Seed priming with either stigmasterol or folic acid significantly increased capsules number comparing the stressed plants. Similar to our results, stigmasterol treatment was found to enhance a partial alleviation of the harmful effects on flax yield caused by salt stress (Hashem et al., 2011).

Fig. 2 also shows that number of seeds was significantly decreased due to drought stress comparing control value. Yield is a result of the integration of metabolic reactions in plants; consequently any factor that influences this metabolic activity at any period of plant growth can affect the yield (Aldesuquy et al., 2009, Hashem et al., 2011). It could be suggested that the decreased yield components in the present work due to drought could be attributed to the detected reduction in the photosynthetic efficiency and, hence, less formation of carbohydrates.

Seed priming with folic acid or stigmasterol significantly increased number of seeds in flax comparing the stressed plants even though values still lower than those of control plants. On the other hand, Abd El-Wahed et al. (2001) found that sitosterol application significantly increased spikelet number/spike and grain weight of wheat. They also recorded that plant yield and grains number/row in maize plant increased with increasing sitosterol concentrations. El-Greedly and Mekki (2005) also stated that the increase in 
seed/plant of the two sesame cultivars and the increase in number and weight of capsules as well as seed weight at high stigmasterol concentration might be due to the increment of growth regulators which improved photosynthetic activities. ElTohamy et al., (2008) highlighted the beneficial effects of vitamins on yield quantity and quality. Emam et al., (2011) found that vitamins significantly increased the yield components of flax plants in terms of number of capsules/plant, number of seeds/capsule, seed yield/plant, seed yield/feddan as well as seed index. Such stimulatory effect was more pronounced in folic acid-treated plants which might be attributed to its effect on regulation of protein and nucleic acid biosynthesis (Andrew et al., 2000).
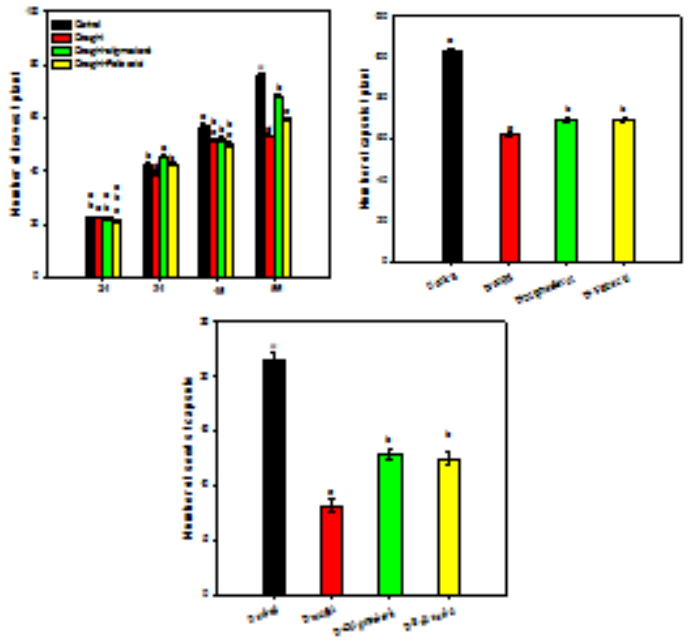

Days After Sawing (DAS)

Fig. 2 Changes in number of leaves, capsules and number of seeds of flax cultivar (Giza9) as a result of drought stress alone or in combination with stigma sterol or folic acid. Data are means of three replicates \pm SE. Bars labeled with different letters are significantly different at $P<0.05$.

Fig. 3 shows the changes in pigments contents in flax as a result of drought by withholding water. There was a general gradual increase in chlorophyll a, chlorophyll $\mathrm{b}$ and carotenoids contents with increasing time of the experiment in the well-watered plants. Drought caused a great decrease in chlorophyll a content as compared to the corresponding control values. Greater was the effect of drought on chlorophyll $b$ followed by chlorophyll a, and then carotenoids. This inhibition increased with increasing time of the experiment. Application of either stigmasterol or folic acid as presoaking overcame this inhibition in chlorophyll a content.

The inhibitory effects of drought on photosynthetic pigments would lead to an inhibition in photosynthesis of plants. Indeed, Kiani et al., (2008) reported that drought causes changes in chlorophyll contents and components and damage photosynthetic apparatus and subsequently inhibits photosynthesis. On the other hand, Hassanein et al., (2012) found that application of stigmasterol alleviated the damage effects of salt stress on photosynthetic pigment contents. In addition, Abd El-Wahed (2001) found that the contents of the photosynthetic pigments $\mathrm{chl} \mathrm{a}$, chl b and carotene were increased in maize as sitosterol concentration increased.

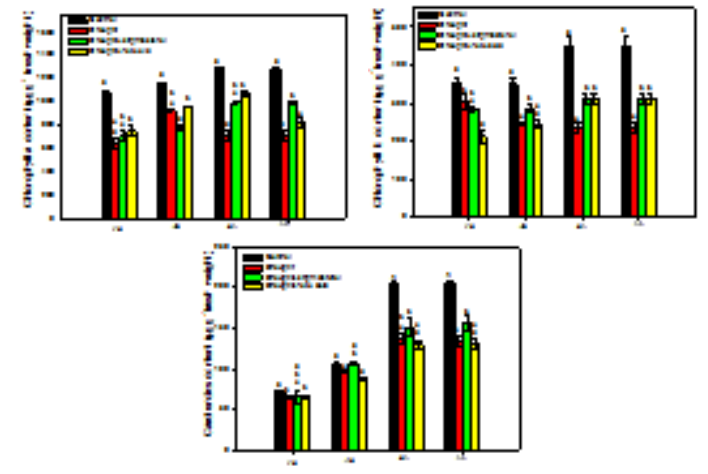

Days After Sawing (DAS)

Fig. 3 Changes in contents of chlorophyll a, chlorophyll $\mathrm{b}$ and carotenoids of flax cultivar (Giza9) as a result of drought stress alone or in combination with stigma sterol or folic acid. Data are means of three replicates \pm SE. Bars labeled with different letters are significantly different at $P<0.05$.

There was a gradual accumulation in total soluble sugars content in flax with increasing time (Fig. 4). Drought decreased total soluble sugars content comparing control values during the first two harvests, thereafter, a slight increase was recorded comparing control values. Presoaking with either stigma sterol or folic acid increased total soluble sugars content in the second harvest comparing stressed plants then a significant decrease was performed in the last two harvests as compared to stressed plants. On the other hand, insoluble sugars content gradually decreased with increasing the experimental time. Drought led to significant decreases in insoluble sugars content, however, presoaking with stigmasterol or folic acid significantly enhanced these contents; the magnitude of accumulation was highest with folic acid. In this account, Emam and Helal (2008) concluded that vitamin treatments had generally favorable effect on the accumulation of total carbohydrate at the expense of the soluble one. Fig. 4 also shows that there was a gradual increase in total soluble protein content with the progress in time. Drought severely inhibited total soluble protein content all over the experimental period. 
Pretreatment with stigmasterol or folic acid enhanced protein accumulation all over the experimental period relative to the stressed plants particularly during the first two harvests. These findings could point to a decline in protein content that might result from an intensified degradation of proteins and/or overall inhibition in protein synthesis under water stress. On the other hand, Yang et al. (2009) indicated an increase in the total soluble protein content in the leaves of two poplar species subjected to an insufficient water supply; this increase was more efficient in the species that was better adapted to drought conditions.

Proline was gradually accumulated with increasing time of the experiment in treated or non -treated plants in flax cultivar (Fig. 5). Drought greatly enhanced proline accumulation all over the experimental period. Either stigmasterol or folic acid pretreatment induced further accumulation of proline all over the experimental period, the magnitude of accumulation was most pronounced with stigmasterol suggesting proline role in osmoregulation for overcoming of drought stress. This amino acid has been reported to play multiple physiological functions in plants subjected to drought, such as osmoregulation, a sink for energy and nitrogen, and a signal of senescence (Filippou et al., 2011).
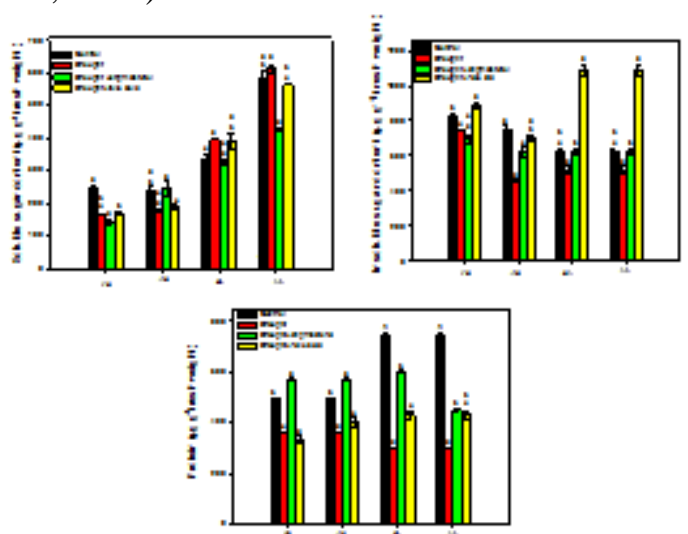

Days After Sawing (DAS)

Fig. 4 Changes in total soluble sugars, total insoluble sugars and protein contents of flax cultivar (Giza9) as a result of drought stress alone or in combination with stigma sterol or folic acid. Data are means of three replicates \pm SE. Bars labeled with different letters are significantly different at $P<0.05$.

As shown in Fig.5, there was a gradual decrease in $\mathrm{H}_{2} \mathrm{O}_{2}$ and lipid peroxidation in the well-watered flax with increasing time. Drought stress alone significantly enhanced $\mathrm{H}_{2} \mathrm{O}_{2}$ accumulation all over the experimental period, however, pretreatment with stigmasterol or folic acid significantly suppressed this accumulation.
On the other hand, drought seemed with no effect on lipid peroxidation in the first harvests then a significant increase in lipid peroxidation was set in during the last two harvests. Presoaking with either stigmasterol or folic acid alleviated this increases in lipid peroxidation.

Drought is a major abiotic stress that produces reactive oxygen (Foyer and Noctor, 2002; Nemat Alla et al. 2008; Nemat Alla et al. 2014). However, plants are able to cope with harsh conditions through up-regulation of antioxidant enzymes for scavenging the produced reactive oxygen species (Nemat Alla et al., 2008; Nemat Alla et al., 2014). In accordance with our results, Emam and Helal. (2008) found that stressed flax seedlings treated with either folic acid, ascorbic acid or coblamin have much better hydrogen peroxide scavenging mechanism as manifested by continuous increase in catalase and peroxidase activities resulting in lower $\mathrm{H}_{2} \mathrm{O}_{2}$ content. Moreover, vitamin treatments have been reported to reduce lipid peroxidation compared stressed plants (Emam and Helal 2008). In conclusion, seed priming with either stigmasterol or folic acid improved -to some extent- growth and yield of flax grown under drought stress. This improvement might result from improvement of photosynthetic apparatus and anabolic processes for standing up carbohydrate formation and protein synthesis. Moreover, the overcome of stress conditions as indicated from the alleviation of oxidative stress synchronous and elevation of proline, the effective parameter as osmoprotectant and osmoregulator support plants to cope with harsh conditions. Further research will be carried out for examining the role of these additives as foliar spray in stressed flax improvement.

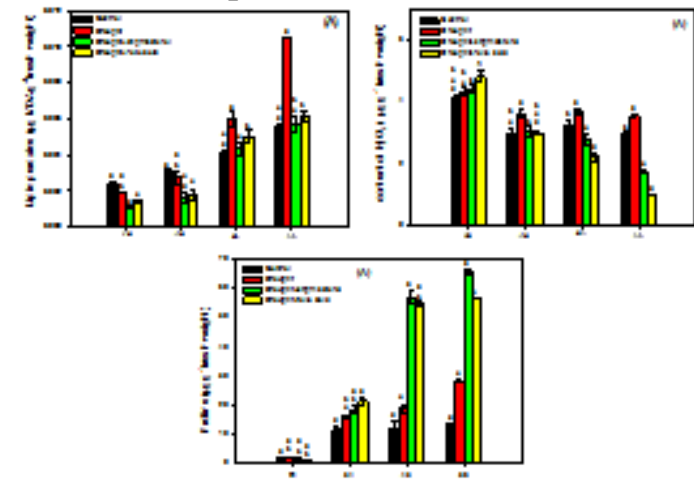

Days After Sawing (DAS)

Fig. 5 Changes in lipid peroxidation, $\mathrm{H}_{2} \mathrm{O}_{2}$ and proline contents of flax cultivar (Giza9) as a result of drought stress alone or in combination with stigma sterol or folic acid. Data are means of three replicates \pm SE. Bars labeled with different letters are significantly different at $P<0.05$. 


\section{References}

Abd El-Wahed, M. S., Ali Z. A., Abdel Hady M S, Rashad S. M. (2001). Physiological and anatomical changes on wheat cultivars as affected by sitosterol. J. AgricSci Mans. Univ. 26(8) 4823-4839.

Ahmadizadeh, M. H., Shahbazi, M. Valizadeh and M. Zaefizadeh (2011).Genetic diversity of durum wheat landraces using multivariate analysis under normal irrigation and drought stress conditions. African J. Agric. Res., 6(10): 2294-2302.

Aldesuquy H. S., Abo-Hamed S. A., Abbas M. A., Elhakem A. H. (2009). Effect of glycine betaine and salicylic acid on growth and productivity of droughted wheat cultivars: 1-Osmolytes in relation to osmotic adjustment and grain yield. J. Environ. Sci. Mans. Univ. 37: 13-33.

ALexieva V., Sergiev I., Mapelli S., Karanov E. (2001). The effect of drought and ultraviolet radiation on growth and stress markers in pea and wheat. Plant Cell Environ. 24:1337-134

Al- Qubaie, A. I. (2012): Response of sunflower cultivar Giza- 102 (Helianthus annuus L.) plants to spraying of some antioxidants. Minia J. of Agric. Res. \& Develop. Vol. 32 (2) pp 10

Andrew W. J., Youngkoo C., Chen X., Pandalai S. G. (2000). Vicissitudes of a vitamin. Recent Res. Dev. Phytochem., 4: 89-98.

Carver R.H., Nash J. G. (2011). Doing data analysis with SPSS version 18, Cendgage Learning.

Bates L.E., Waldren R. P, Teare I. D. (1973). Rapid determination of free proline for water stress studies. Plant and Soil 39: 205-207.

Bradford M.M. (1976). A Rapid and Sensitive Method for The Quantification of Microgram Quantities of Protein Utilizing.The Principle of Protein Dye Binding. Analytical Biochemistry. 72: 248-54

Candan N., Tarhan L., (2003). The correlation between antioxidant enzyme activities and lipid

peroxidation levels in Mentha pulegium organs grown in $\mathrm{Ca} 2+, \mathrm{Mg} 2+, \mathrm{Cu} 2+, \mathrm{Zn} 2+$ and $\mathrm{Mn} 2+$

stress conditions. Plant Sci. 163, 769-779.

Demirevska K, Zasheva D, Dimitrov R, SimovaStoilova L, Stamenova M, Feller U (2009). Drought stress effects on Rubisco in wheat: changes in the Rubisco large subunit. Acta Physiol. Plant., 31: 1129-1138.

El- Greedly NH, Mekki BB (2005). Growth, yield and endogenous hormones of two sesame (SesamumindicumL.) cultivars as influenced by stigmasterol. J. Appl. Sci.Res.1(1): 63-66.

El-Tohamy WA, El-Gready NHM (2007). Physiological responses, growth, yield and quality of snap beans in response to foliar application of yeast, vitamin $\mathrm{E}$ and zinc under sandy soil conditions. Aust. J. Basic Appl. Sci., 1(3): 294-299.
Emam M. M., El-Sweify A. H. and Helal N. M. (2011). Efficiencies of some vitamins in improving yield and quality of flax plant. Afri.c J. Agricult. Res. 6(18): 4362-4369.

Emam, M.M. and Helal,N.M. (2008). Vitamins minimize the salt induced oxidative stress hazards.

Austra. J. Basic Appli. Sci, 2(4): 1110-1119.

Fardet, A.; Rock, E. and Christian, R. (2008). 1s the in vitro antioxidant potential of whole- grain cereals and cereal produces well reflected in vivo. J. Cereal Sci. 48: $258-276$.

Farooq, M., A. Wahid, N. Kobayashi, D. Fujita and S.M.A. Basra, (2009). Plant drought stress: effects, mechanisms and management. Agron. Sustain. Dev., 29: 185-212

Filippou P., Chrystalla A., VasileiosF. (2011). Effect of drought and rewatering on the cellular status and antioxidant response of Medicago truncatula plants. Plant Signaling \& Behavior 6(2): 270-277,

Foyer C. H. and NoctorG. (2002). Oxygen processing in photosynthesis: regulation and signaling. New Phytol.146: 359-388.

Hartmann MA. (2009). Plant sterols and the membrane environment. Trends Plants Sci. 3:170-175.

Hasnaa S. Ayad, Karima M. Gamal El-Din and Fatma Reda. (2009). Efficiency of Stigmasterol and $\infty$ Tocopherol Application on Vegetative Growth, Essential Oil Pattern, Protein and Lipid Peroxidation of Geranium (Pelargonium Graveolens L) J. Applied Sciences Research 5 (7): 887-892.

Hashem H.A, Bassuony F.M, Hassanein R.A. Baraka D.M. and Khalil R.R. (2011).Stigmasterol seed treatment alleviates the drastic effect of $\mathrm{NaCl}$ and improves quality and yield in flax plants AJCS 5(13):1858-1867.

Hassanein1 R. A,.Hashem1 H.A, and. Khalil R. R (2012). Stigmasterol treatment increases salt stress tolerance of faba bean plants by enhancing antioxidant systems.POJ. 5(5):476-485).

Ibrahim H.M. (2009). Effect of sowing date and Nfertilizer levels on seed yield, some yield components and oil content in flax. Alex J.Agric Res. 54(1): 19-28.

Jaleel, C.A., Manivannan, P., Wahid, A. (2009). Drought stress in plants: a review on morphological characteristics and pigments composition. Int. J. Agr. Biol. 11: 100-105.

Kiani, S.P., P. Maury, A. Sarrafi and P. Grieu.(2008). QTL analysis of chlorophyll fluorescence parameters in sunflower (Helianthus annuus L.) under well-watered and water-stresse conditions. Plant Sci., 175: 565-573.

Lichenthaler H. K.,Wellbrn A. R .(1983). Determination of total carotenoids and chlorophylls $\mathrm{a}$ and $\mathrm{b}$ and leaf extracts in different solvents. In: 
Abstracts of the International Congress on photosynthesis Brussles, pp 415.

Naheif E. M. 2013. Behaviour of Wheat Cv. Masr-1 Plants to Foliar Application of Some Vitamins. Nature and Science, 11: (6) 1-5.

Nakayama N., H. Saneoka R.E.A. Moghaieb G.S. Premachandra and K. Fujita. (2007). Response of growth, photosynthetic gas exchange, translocation of 13C-labelled photosynthate and $\mathrm{N}$ accumulation in two soybean (Glycine max L. Merrill) cultivars to drought stress. Int. J. Agric. Biol., 9: 669-674.

Nemat Alla M. M., Abogadallah G M, Badran E G, Nada R M (2014). Differential tolerance of two wheat cultivars to $\mathrm{NaCl}$ is related to antioxidant potentialities. Brazilian J. of Botany, 37:207-215.

Nemat Alla M. M, Hassan N. M., El-Bastawisy Z. M. (2008). Changes in antioxidants and kinetics of glutathione-S-transferase of maize in response to isoproturon treatment. Plant Biosystems 142:5-16.

Nouri-Ganbalani, A., Nouri-GanbalaniG.and D. Hassanpanah.(2009). Effects of drought stress condition on the yield and yield components of advanced wheat genotypes in Ardabil, Iran. J. Food Agric. Environ., 7(3\&4): 228-234.

Piironen V., Lindsay D.G, Miettinen T.A., Toivo J., Lampi A.M. (2000). Plant sterols: biosynthesis, biological function and their importance to human nutrition. J.Sci Food Agric, 80:939-966.

Rafiei M.,Shirvan, Asgharipur M.R. (2009).Yield reaction and morphological characteristics of some mung bean genotypes to drought stress. J. Mod. Agric. Knowl. 5(15):67-76.
Rao S.S.R, Vardhini B.V., Sujatha E., Anuradha S. (2002). Brassinosteroids a new class of plant phytohormones.Curr. Sci. 82: 1239-1244.

Razmjoo, K., P. Heydarizadeh and Sabzalian M.R. (2008). Effect of salinity and drought stresses on growth parameters and essential oil content of Matricaria chamomile.Int. J. Agric. Biol., 10: 451454.

Sankar B., Jaleel C.A., Manivannan P., Kishorekumar A., Somasundaram R., Panneerselvam R. (2007). Drought induced biochemical modifications and proline metabolism in Abelmoschusesculentus (L.) Moench Acta Bot. Croat. 66:43-56.

Sayar R., Bchini H., Mosbahi M., Khemira H. (2010). Response of durum wheat (Triticum durum Desf.) growth to salt and drought stresses. Czech J. Genet.Plant Breed. 46: 54-63.

Schortermeyer M., stamp P.,Feil B.(1997). Ammonium tolerance and carbohydrates status in maize cultivars. Ann. Bot.79:25-30.

Srivalli B., Sharma G., Khanna-Chopra R. (2003). Antioxidative defense system in an upland rice cultivar subjected to increasing intensity of water stress followed by recovery. Physiol. Plant. 119:503-12.

Verbruggen N., Hermans C. (2008). Proline accumulation in plants: a review. Amino Acids 35: 753759.

Yang, F., XuX., Xiao X. and. LiC. (2009). Responses to drought stress in two poplar species originating from different altitudes. Biol. Plant., 53: 511-516 
الملخص العربي

عنوان البحث: دور ستيجماستيرول وحمض الفوليك فى تحسين النمو وانتاجية الكتان تحث ظروف الجفاف

نعمت محمد حسن ، زينب محمود لبسطويسى ، ايناس جمال بلران ، ابتسام حمادى

قسم النبات و الميكربيولوجى - كلية العلوم - جامعة دمياط

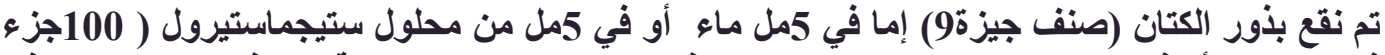

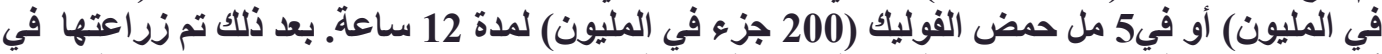

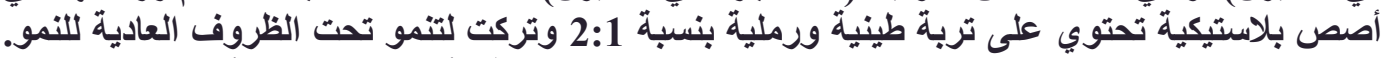

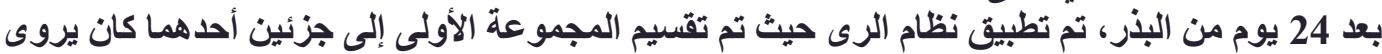

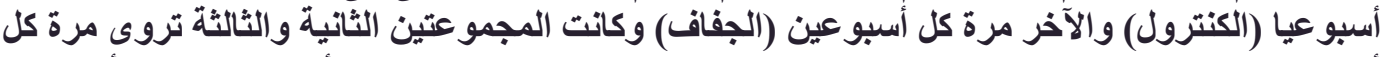

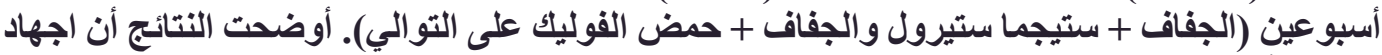

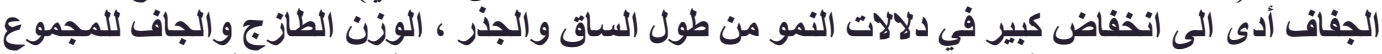

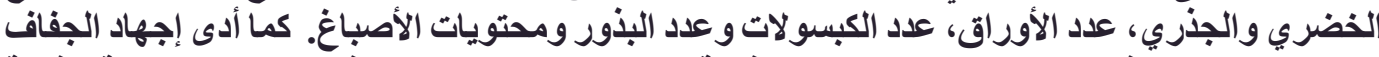

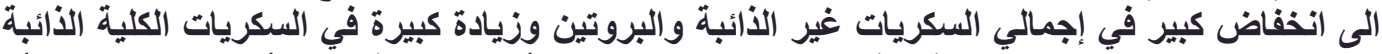

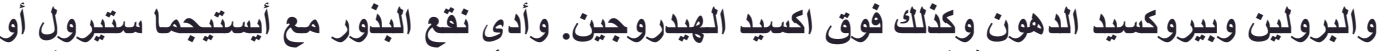

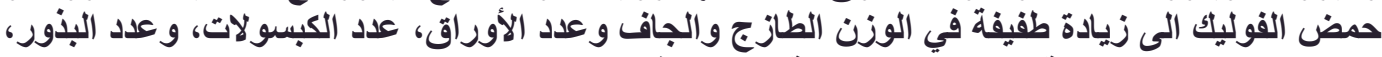

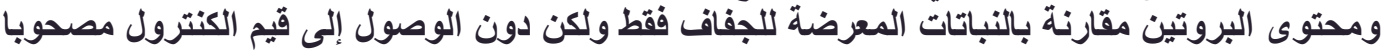

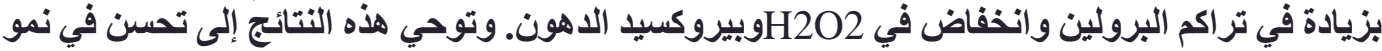

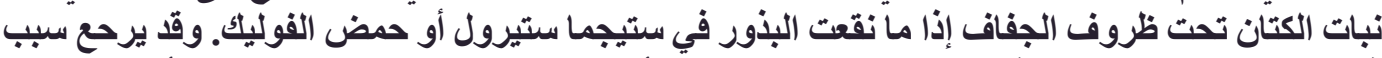

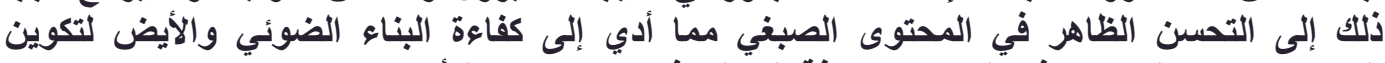
الكربو هيدرات والبروتين في ألنبات بالإضافة إلى التعافي من الإجهاد التأكسدي. 